GA-A24505

\title{
FABRICATION OF WINDOW SADDLES FOR NIF CRYOGENIC HOHLRAUMS
}

\author{
by \\ E. GIRALDEZ and J.L. KAAE
}




\section{DISCLAIMER}

This report was prepared as an account of work sponsored by an agency of the United States Government. Neither the United States Government nor any agency thereof, nor any of their employees, makes any warranty, express or implied, or assumes any legal liability or responsibility for the accuracy, completeness, or usefulness of any information, apparatus, product, or process disclosed, or represents that its use would not infringe privately owned rights. Reference herein to any specific commercial product, process, or service by trade name, trademark, manufacturer, or otherwise, does not necessarily constitute or imply its endorsement, recommendation, or favoring by the United States Government or any agency thereof. The views and opinions of authors expressed herein do not necessarily state or reflect those of the United States Government or any agency thereof. 


\title{
FABRICATION OF WINDOW SADDLES FOR NIF CRYOGENIC HOHLRAUMS
}

\author{
by \\ E. GIRALDEZ and J.L. KAAE
}

This is a preprint of a paper presented at the 15th Target Fabricartion Specialists Meeting, Gleneden Beach, Oregon, June 1-5, 2003 and to be published in Fusion Science and Technology.

\author{
Work supported by \\ the U.S. Department of Energy \\ under Contract No. DE-AC03-01SF22260
}

\section{GENERAL ATOMICS PROJECT 30095} SEPTEMBER 2003 


\title{
FABRICATION OF WINDOW SADDLES FOR NIF CRYOGENIC HOHLRAUMS
}

\author{
Emilio Giraldez and James L. Kaae \\ Center for Target Component Fabrication and Fabrication Development \\ Inertial Fusion Technology \\ General Atomics \\ PO Box 85608 \\ San Diego, CA 92186-5608
}

\begin{abstract}
A planar diagnostic viewing port attached to the cylindrical wall of the NIF cryogenic hohlraum requires a saddle-like transition piece. While the basic design of this window saddle is straightforward, its fabrication is not, given the scale and precision of the component. We solved the problem through the use of a two segment copper mandrel to electroform the gold window saddle. The segments were micro-machined using a combination of single-point diamond turning and single point diamond milling. These processes as well as the electroplating conditions, final machining and mandrel removal are described in this paper.
\end{abstract}

\section{INTRODUCTION}

The current design for indirect-drive ignition targets for the National Ignition Facility (NIF) consists of a target capsule with a solid-fuel layer inside a cryogenic hohlraum, Figure $1^{1}$. Thermal shimming of the cryogenic hohlraum creates a thermal profile that results in a uniform solid-fuel layer inside the target capsule. Preliminary fuel loading experiments require that the cryogenic hohlraums have viewing ports to diagnose the presence of liquid fuel and analyze the layering of the solid-fuel inside the target capsule. However, containment of the gaseous atmosphere in the hohlraum requires that all the openings (laser entrance holes and viewing ports) be covered with thin polymer windows. To facilitate sealing of the viewing port, a component known as a window saddle is attached to the cryogenic hohlraum at its axial center. The window saddle is made out of gold, as is the hohlraum. Figure 2 is a CAD rendering of a NIF cryogenic hohlraum with two window saddles.

The window saddle, Figure 3, can be described as a cylinder with flanges at either end. One flange is flat, where the polymer window is attached, while the other flange is curved so that it can be attached to the side of the cryogenic hohlraum. Table I gives the dimensions of the window saddle.

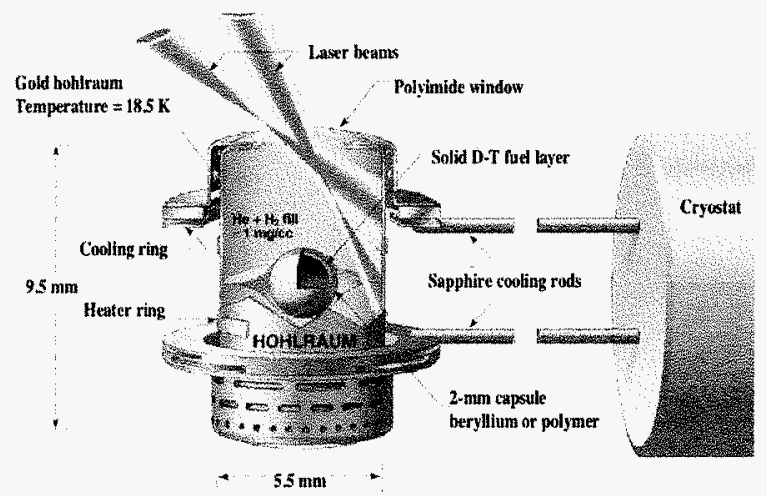

Figure 1. NIF cryogenic hohlraum capsule assembly.

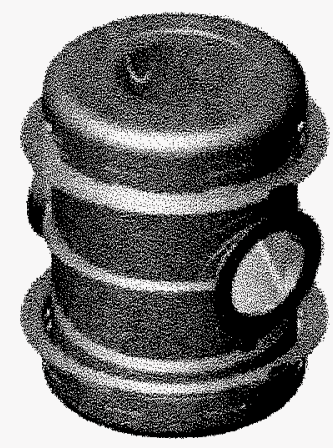

Figure 2. NIF cryogenic hohlraum with window saddles.

\section{MANDREL FABRICATION}

We have used an electroforming technique ${ }^{2}$ to fabricate the window saddle (many of the target components utilized in Inertial Confinement Fusion (ICF) also are fabricated by electroforming). The electroforming 
process utilized at the Center for Target Component Fabrication at General Atomics starts with the micromachining of oxygen-free-high-conductivity (OFHC) copper stock to precise specifications using single-point diamond turning and milling to make a mandrel of the required shape. The copper mandrel is then electroplated with the desired metal, typically gold. Finally the copper mandrel is removed by dissolution in acid, leaving behind the finished component.

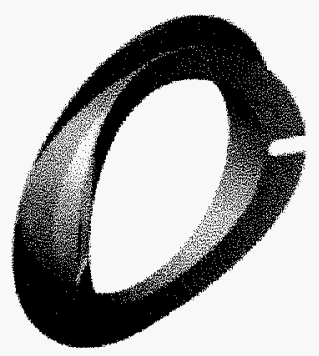

Figure 3. CAD rendering of a window saddle.

Table I. Typical dimensions of a window saddle for a NIF cryogenic hohlraum.

\begin{tabular}{|l|l|}
\hline Window ID & $2.38 \mathrm{~mm}$ \\
\hline Flat Flange OD & $3.50 \mathrm{~mm}$ \\
\hline Curved Flange OD & $3.10 \mathrm{~mm}$ \\
\hline $\begin{array}{l}\text { Curved Flange Curvature } \\
\text { (R) }\end{array}$ & $2.80 \mathrm{~mm}$ \\
\hline Thickness & $30 \mu \mathrm{m}$ \\
\hline Min height & $0.22 \mathrm{~mm}$ \\
\hline
\end{tabular}

\section{II.A. Machining Segments}

Due to the shape, size and precision of the window saddle, the mandrel would be extremely difficult to be micro-machine as a single unit. Rather, we chose to machine two segments and then to assemble them to make up the window saddle mandrel. Figure 4 shows $\mathrm{CAD}$ renderings of the two segments that make up the mandrel. One segment consists of two coaxial cylinders of different diameters. The diameter of the small cylinder, also referred to as the pin, matches the inside diameter of the window saddle. The other segment consists of a curved section that matches the curvature of the curved flange. A hole is machined in the center of the curved section and is used in aligning and securing the two segments together. Figure 5 shows a CAD rendering of the assembled mandrel.

First the curved segment was turned down from stock OFHC copper rod on a PRECITECH lathe. The turned rod was then moved to a KERN 5-axis micro-mill where a hole was milled using a flat end diamond tool. A flat was milled on the backside, perpendicular to the hole, to expose the hole from the back. The diameter of the hole and the thickness of the curved section were measured very accurately $( \pm 1 \mu \mathrm{m})$ on a NIKON measuring microscope with a QUADRA-CHEK digital readout system. These dimensions are needed to micro-machine the pin segment. Figure 6 is a photograph of the micromachined curved segment with the assembly hole. The flat on the left of the hole is used as a guide when sawing off the curved section from the copper rod.
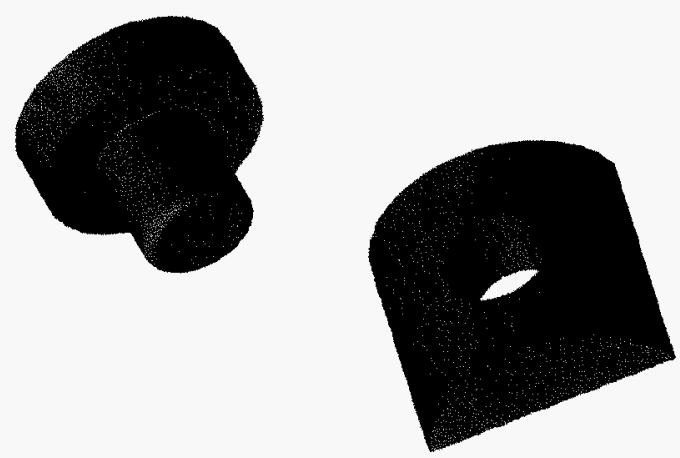

Figure 4. Segments that make up the window saddle mandrel.

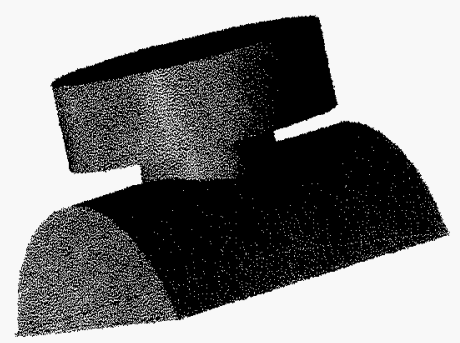

Figure 5. Window saddle mandrel assembly.

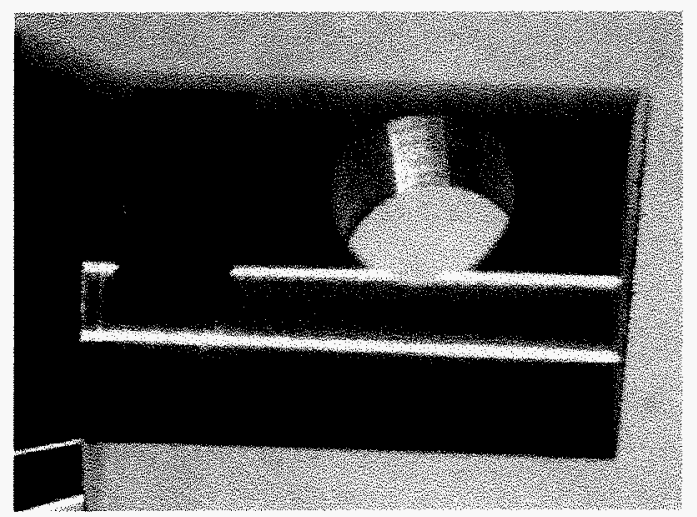

Figure 6. Photograph of micro-machined curved segment. 
The pin was turned down to a diameter based on the diameter of the hole and to a length that is equal to the thickness of the curved section plus the minimum height between the flat flange and curved flange. Figure 7 is a photograph of the micro-machined pin. The end of the pin was machined with a fillet, which is used for alignment of the two segments during assembly.

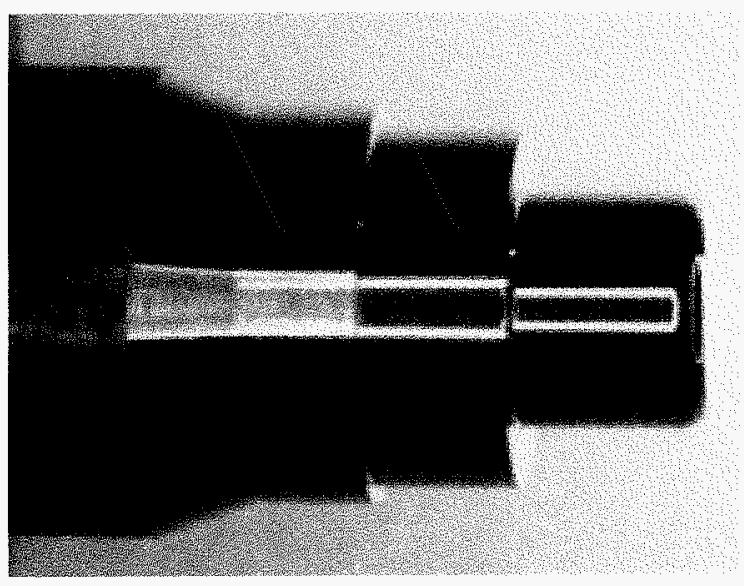

Figure 7. Photograph of micro-machined pin segment.

\section{II.B. Assembling Segments}

The two segments that make up the window saddle mandrel were assembled by pushing the pin into the hole until the pin bottomed out. Several types of fits (running, force, and shrink) ${ }^{3}$ were tried between the pin and the hole. The best results were obtained with shrink fit with an interference of $4 \mu \mathrm{m}$ between the diameter of the pin and diameter for the hole. Shrink fitting eliminates deformation and abrasion of the pin as it is pushed against the sides of the hole during assembly with this technique. The pin segment was cooled in liquid nitrogen to $-196^{\circ} \mathrm{C}$ and the curved segment was heated to $100^{\circ} \mathrm{C}$ with a heat gun. This temperature difference is sufficient for the pin to fit inside the hole without any interference prior to assembly. The assembly was carried out with the aid of an alignment fixture and an arbor press.

\section{II.C. Finish Machining of Mandrel}

The assembled mandrel was placed back on the lathe and aligned to better than $1 \mu \mathrm{m}$ runout utilizing an electronic dial indicator. The curved section and the larger cylinder on the pin segments were single-point diamond turned down to a diameter that is $0.1 \mathrm{~mm}$ larger than the diameter of the curved flange and flat flange respectively. A completed window saddle copper mandrel is shown in Figure 8.

\section{ELECTROPLATING}

Electroplating the copper mandrel with gold electroforms the window saddle. Before plating, the copper mandrel was cleaned to remove any surface oxides $^{4}$.

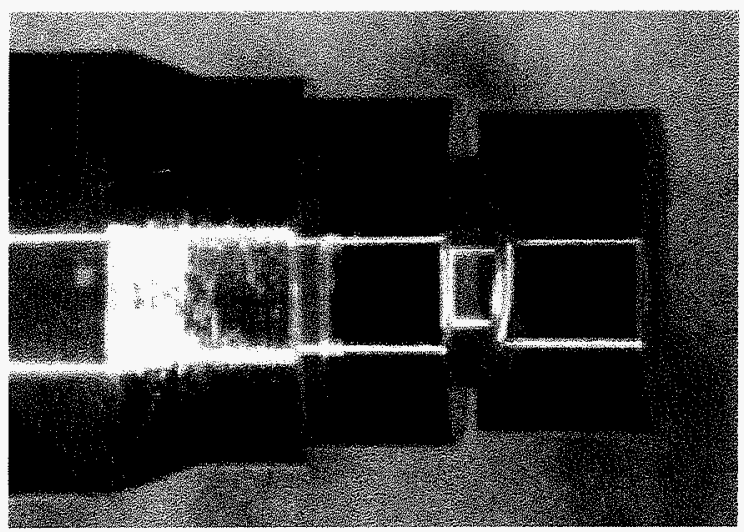

Figure 8. Photograph of finished window saddle copper mandrel.

Initial gold plating trials showed that if there are any gaps in the fit between the pin and the hole, gold plates in the gaps. On dissolution of the copper this appeared as thin gold protrusions on the surface of the curved flange. To overcome this problem the copper mandrel was plated with 4-5 $\mu \mathrm{m}$ of copper to fill in the gaps. The diameter of the pin and diameter of the hole were adjusted accordingly to compensate for the added copper thickness from to the copper plating step.

The mandrel was gold plated to a thickness of $30 \mu \mathrm{m}$. The gold thickness was determined by measuring the diameter of the curved section of the mandrel before and after plating using a laser micrometer (Z-Mike 1210).

\section{FINAL MACHINING}

The electroplated copper mandrel was placed on the lathe one last time for final machining. The gold, on what will be the flat flange and curved flange was single-point diamond turned to the corresponding finish diameters. Next the two alignment slots on the curve flange were micro-machined on the KERN micro-mill. The slots were machined using a diamond coated square end carbide end mill ${ }^{5}$.

The locations of the slots were determined optically to within $\pm 5 \mu \mathrm{m}$ using a microscope attachment on the micro-mill. The slots were machined to a depth that was previously determined by measuring the distance from the 
pin to the surface of the curved flange with a NIKON interference microscope.

\section{COPPER MANDREL REMOVAL}

The copper mandrel was dissolved in a solution of nitric acid. The finished electroformed window saddle was removed from the acid solution, rinsed several times with de-ionized water followed by a rinse with ethanol and dried with filtered dry air. Figure 9 is a photograph of the finished window saddle.

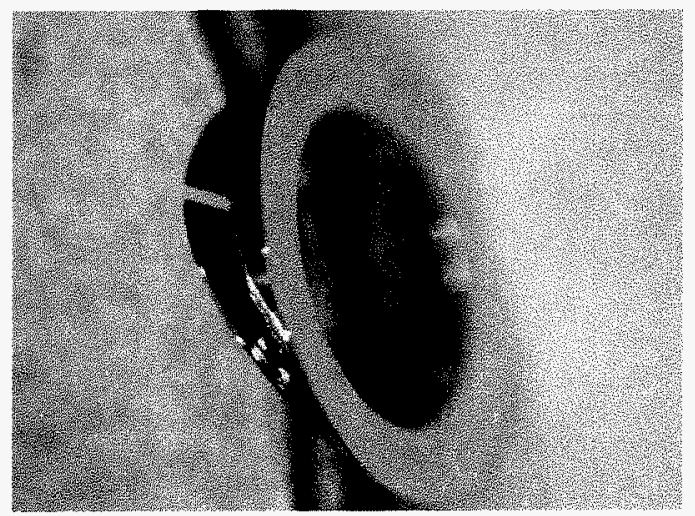

Figure 9. Electroformed window saddle.

\section{CONCLUSIONS}

The Center for Target Component Fabrication at General Atomics has devised a technique to make complex ICF components that because of their shape, scale and precision cannot be micro-machined by turning or milling alone. The process consists of fabricating individual segments of a mandrel using a combination of turning and milling and assembling these segments together prior to electroforming.

\section{ACKNOWLEDGMENTS}

This work was supported by the U.S. Department of Energy under Contract No. DE-AC03-01SF22260. We want to thank the following people: Dave Woodhouse for the copper and gold electroplating, and Clyde Shearer for the setting up the assembly rig, staff members in the Center for Target Component Fabrication at General Atomics, Jerry Stewart from Schafer Corp. for providing the CAD renderings of the window saddle, Jorge Sanchez from LLNL the principal investigator on the design, fabrication and testing of prototype NIF cryogenic hohlraums.

\section{REFERENCES}

1. SANCHEZ, J.J. AND GIEDT, W.H., "Temperature Control Sensitivity Variations of Cylindrical Hohlraums with Capsule Thermal Conductivity," $12^{\text {th }}$ Target Fabrication Specialist's Meeting, Jackson Hole, Wyoming (1998).

2. SPIRO, P., "Electroforming: a Comprehensive Survey of Theory, Practice and Commercial Applications," Published by Robert Draper Ltd, Teddington, $2^{\text {nd }}$ edition, 1971.

3. Machinery's Handbook 25, Industrial Press Inc., New York, 1996.

4. ELSNER, F., "Thickness Distribution for Gold and Copper Electroformed Hohlraums," Fusion Technology, 35, 2, 81 (1999).

5. GIRALDEZ, E, "Cutting tool selection and tool life when micro-milling rolled high-purity gold," $15^{\text {th }}$ Target Fabrication Specialist's Meeting, Gleneden Beach, Oregon (2003). 